\title{
Relationship between Parental Mediation and Cyberbullying among Children and Adolescents
}

\author{
Sergio A Castano ${ }^{1}$, Katty Millán Osorio ${ }^{2}$ \\ Corporación Universitaria Minuto de Dios ${ }^{1}$
}

\begin{abstract}
Cyberbullying is defined as a form of online aggression and a growing phenomenon widespread. Its impact is greater than traditional bullying as it results in more severe mental health problems specially among children and adolescents. This research tried to identify the relationship between cyberbullying and parental mediation. We applied The Kids on Line interview to describe risks and opportunities in the use of Internet in children and adolescents. Results indicated that parental mediation and better quality of relationships are associated with less problematic use of the Internet and less presence of social risk behaviors, drug use, aggression among adolescents and cyberbullying.
\end{abstract}

Keywords: Cyberbullying, parental mediation, children, adolescents 